\title{
DEVELOPMENT OF UDIMET 720 FOR HIGH STRENGTH DISK APPLICATIONS
}

\author{
F. E. Sczerzenie and G. E. Maurer \\ Special Metals Corporation \\ New Hartford, NY 13413
}

USA

\begin{abstract}
Sumina ry
Udimet 720 is a cast-wrought nickel base superalloy which was originally used for land based gas turbine blades. Work is being done to develop this alloy for high strength disks applications. Hot tensile tests were preformed to define temperature and strain rate parameters for conventional, hot die and superplastic forging. This information was used to select forging parameters for disk type pancakes. Heat treatments were developed to produce mechanical properties suitable for disks. Microstructure and hot tensile properties are reported for various heat treatments. Tensile and stress rupture properties of U720 compare favorably to high strength $\mathrm{P} / \mathrm{M}$ disk alloys. The production of fine grained U720 billet by usc of the VADER (Vacuum $A r c$ Double Electrode Reme1t) process offers the potential to produce large disks from a cast-wrought high strength supera1 1oy.
\end{abstract}

\section{Introduction}

U720 is a high strength corrosion resistant nickel base superalloy precipitation strengthened by $\mathrm{\gamma} ; \mathrm{Ni} / \mathrm{Ti}(\mathrm{A} 1)$ and solid solution strengthened by $\mathrm{Mo}, \mathrm{W}, \mathrm{Cr}$, and $\mathrm{Co}$. The composition of $\mathrm{U} 720$ is compared to several high strength blade and disk alloys in Table I. U720 was originally developed for land based gas turbine blades. When solutioned at $1168^{\circ} \mathrm{C}$, stabilized and double aged, U720 has strength and stress rupture properties comparable to IN738 at temperatures from 593 to $871^{\circ} \mathrm{C}$. However, U720 is unique in that it has superior stress corrosion resistance ip low temperature $\left(704^{\circ} \mathrm{C}\right)$ sulfate/chloride environments. Whitlow et a1. have shown that U720 retains a much higher percentage of its rupture life when exposed to a mixture of $\mathrm{Na}_{2} \mathrm{SO}_{4}, \mathrm{MgSO}_{4}$ and $\mathrm{NaCl}$ than Udimet 710 , U500, IN738, IN939 and other Ni-base blading alloys. The explanation for this is found in the alloy chemistry and microstructure. U720 contains $0.035 \mathrm{C}$ and $0.033 \mathrm{~B}$. The stabilization heat treatments precipitate a combination of $\mathrm{TiC}, \mathrm{Mo}_{2} \mathrm{~B}_{3}$ and $\mathrm{Cr}_{23}(\mathrm{C}, \mathrm{B})_{6}$ on grain boundaries, Figure 1 . This structure is believed to inhibit stress enhanced diffusion of sulfur and oxygen along grain boundaries and thereby retard crack growth in stress corrosion environments. A parallel benefit of the U720 chemistry and grain boundary structure is enhanced impact resistance in long term service. Table II shows that $U 720$ impact resistance actually increases after a 10,000 hour 
TABLE I. CHEMISTRY OF Ni-BASED SUPERALLOYS (Weight \%)

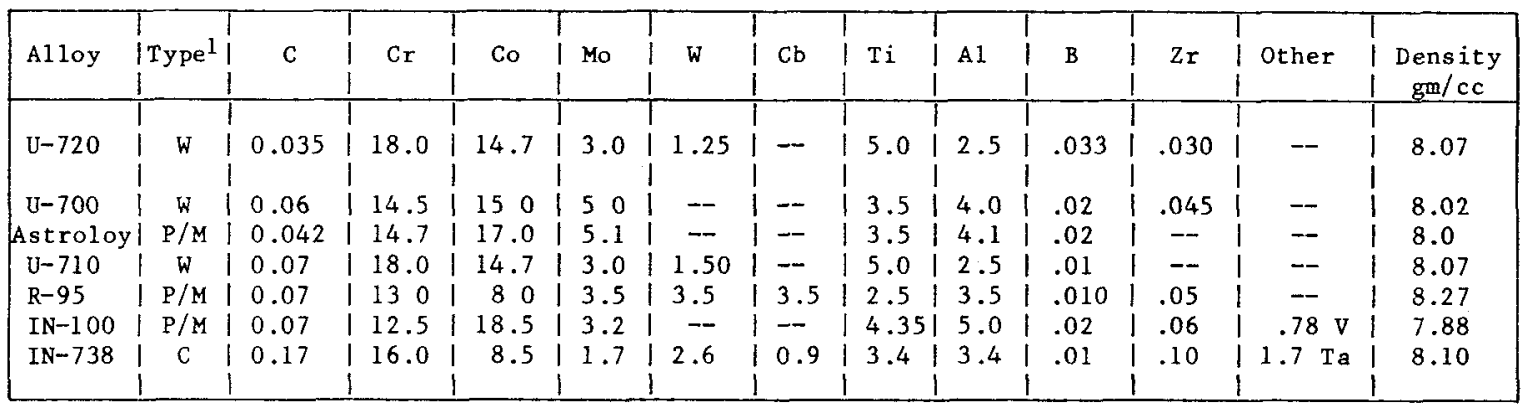

1 Type: $C=$ Cast, $W=$ Wrought, $P /$ F=Powder Metallurgy

exposure at $871^{\circ} \mathrm{C}$ compared to the severe degradation of impact resistance of U710. Cooper et $a 1 .{ }^{2}$ have suggested that the precipitation of $\mathrm{Cr}_{23}(\mathrm{C}, \mathrm{B})_{6}$ during heat treatment impedes the formation of $\mathrm{Cr}_{23} \mathrm{C}_{6}$ in service environments and thereby improves impact resistance. The impact resistance of other high strength superalloys is reported to decrease similarly to that of U710.

This work on the development of U720 for high strength disk applications was based on the realization that reducing the solution temperature in combination with a modified aging treatment raises 4720 yield strength substantially in the range of 650 to $760^{\circ} \mathrm{C}$. This is shown in Table III where Heat Treatment $B$ is the standard U720 blading heat treatment and heat treatment IV is an Astroloy disk heat treatment. The purpose of the present paper is to report on the development of thermomechanical processes and heat treatments of $U 720$ for disk applications.

\section{Material and Testing Bar Structure}

U720 is a cast-wrought alloy made by vacuum induction melting followed by vacuum arc remelting. Ingot is cogged or hot extruded to billet and then rolled to bar. As-rolled bar structure is fine grained typically ASTM 13 with an average grain diameter of 4 microns. The bar structure consists of a $\gamma$ matrix with a bimodal distribution of $\gamma^{\prime}$, Figure 2 . Coarse $\gamma^{\prime}$ with a particle size of 2 to 3 microns is found at the grain boundaries. There is a also an intragranular distribution of fine fluted $\gamma^{\prime}$ with a particle size of 0.25 to 1.0 micron.

\section{Experimental Procedures}

Hot tensile tests were performed to determine the optimum working temperature for U720. To simulate high speed press forging conditions the samples wcre preheated to various temperatures and tested on-cooling at a stroke rate of $5 \mathrm{~cm} \mathrm{sec}^{-1}$.

To simulate hot die forging a second series of slow speed hot tensile tests were done at a stroke rate of $0.02 \mathrm{~cm} \mathrm{sec}^{-1}$. A third series of tensile tests was done with changes in stroke rate from $2 \times 10^{-4} \mathrm{~cm} \mathrm{sec}^{-1}$ to $1.3 \times 10^{-1} \mathrm{~cm} \mathrm{sec}$ to characterize the superplastic behavior of U720 bar. 4

TABLE II - CHARPY V NOTCH IMPACT

\begin{tabular}{lcc} 
ALLOY & AS-HEAT TREATED & AFTER 10,000 HR AT $871^{\circ} \mathrm{C}$ \\
\hline U720 & $1.66 \mathrm{Kg} \mathrm{m}$ & $1.94 \mathrm{Kg} \mathrm{m}$ \\
U710 & $2.22 \mathrm{Kg} \mathrm{m}$ & $.55 \mathrm{Kg} \mathrm{m}$
\end{tabular}




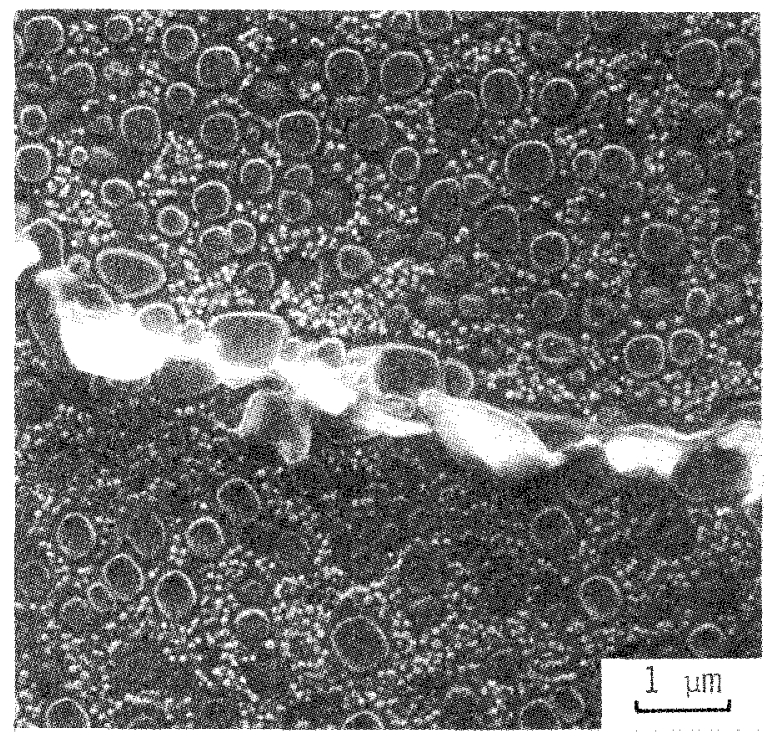

Figure 1. Microstructure of $U 720$ after applying blade heat treatment $(\mathrm{HT}-\mathrm{B})$.

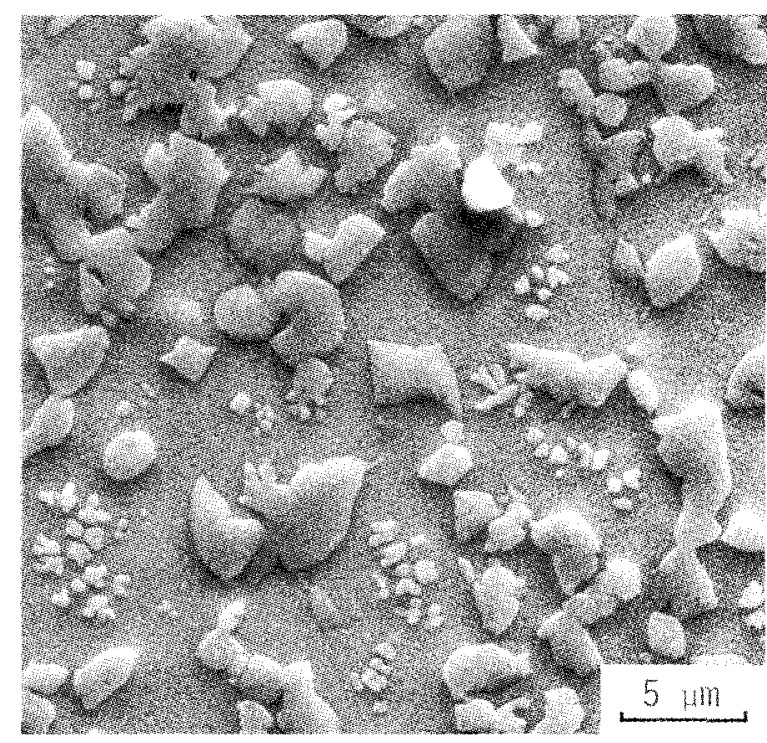

Figure 2. Microstructure of U720 in the as-rolled condition.

Hot die forged pancakes, $15.25 \mathrm{~cm}$ diameter by $3.8 \mathrm{~cm}$ thick, were made from $7.6 \mathrm{~cm}$ diameter bar. The effect of solution temperature was determined using coupons cut from pancakes. Cooling rate effects were determined by heat treatment of full size pancakes.

\section{Results and Discussion}

Hot Workability

Figure 3 shows the effect of preheating temperature on the yield strength and ductility of $U 720$ at $982^{\circ} \mathrm{C}$ for on cooling tensile tests that simulate conventional preheating and forging. Yield strength was calculated from an X-Y plot of a digital high speed oscilloscope record of the test. The data illustrates several important features of forging $U 720$ and other high strength superalloys. First ductility is low and yield strength is high when the alloy is heated close to the $\gamma^{\prime}$ solvus $\left(1155^{\circ} \mathrm{C}\right)$. When preheat temperature is reduced to $1107^{\circ} \mathrm{C}$ or lower, ductility increases into the forgeable range ( $\mathrm{RA} \geq 30 \%$ ) and there is a concurrent reduction in yield strength.5 The explanation for this is that higher heating temperatures cause greater $\gamma^{\cdot}$ solutioning which results in grain growth and the precipitation of finer $\gamma^{\prime}$ on cooling. Grain coarsening reduces ductility and fine $\gamma^{\prime}$ increases strength.

Figure 4 shows the very high tensile elongations with uniform reductions of area that were observed in the slow speed tensile tests from

TABLE III - COMPARISON OF $649^{\circ} \mathrm{C}$ TENSILE PROPERTIES FOR U720

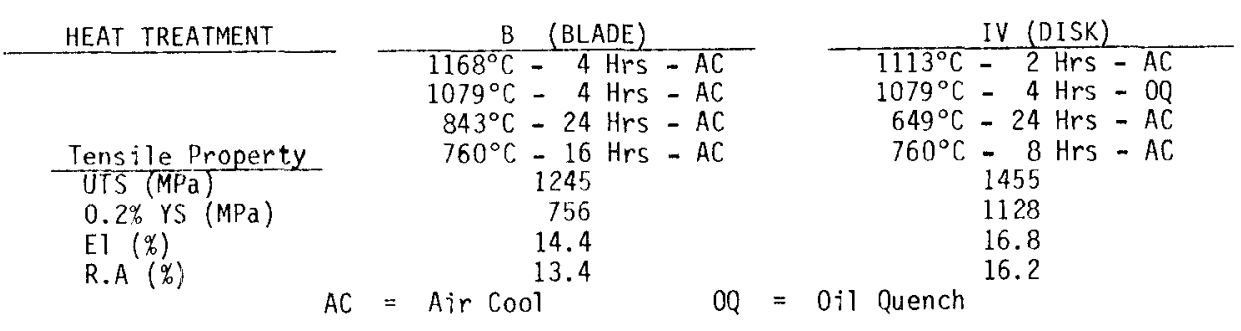


1010 through $1121^{\circ} \mathrm{C}$. These tests were terminated at the maximum stroke capability of the test machine. Reduced tensile elongation with a marked tendency for necking occurred at higher and lower temperatures.

Superplasticity is usually explained in terms of the power law equation for stress as a function of strain rate

$$
\sigma=K \dot{\varepsilon}^{m}
$$

where $m$ is the strain rate sensitivity and

$$
m=\frac{\delta \ln \sigma}{\delta \ln \dot{\varepsilon}}
$$

Figure 5 a shows the transition strain rate from Region II, superplastic, to Region III, conventional or hot die forging, varies as a function of temperature. The transition strain rate at $1010^{\circ} \mathrm{C}$ is about a factor of 10 lower than found for extruded $P / M$ superalloys and this difference can be explained in terms of the coarser grain size of extruded and rolled $U 720.6$ Figure $5 \mathrm{~b}$ shows that an $\mathrm{m}$ of 0.5 or higher can be achieved depending on the selection of temperature and strain rate. The peak $\mathrm{m}=0.68$ was achieved at $1121^{\circ} \mathrm{C}$ with a more ideal superplastic structure. At this temperature the bimodal $\gamma^{\prime}$ of the as-rolled bar is partially solutioned to a single coarse intergranular distribution of $\gamma^{-}$. This type of information has been used to develop hot die forging practices for 0720 . Figure 6 shows a macroetched section of a hot die forged U720 pancake made from $7.62 \mathrm{~cm}$ diameter bar. The metal temperature was $1107^{\circ} \mathrm{C}$ and the die temperature was $954^{\circ} \mathrm{C}$.

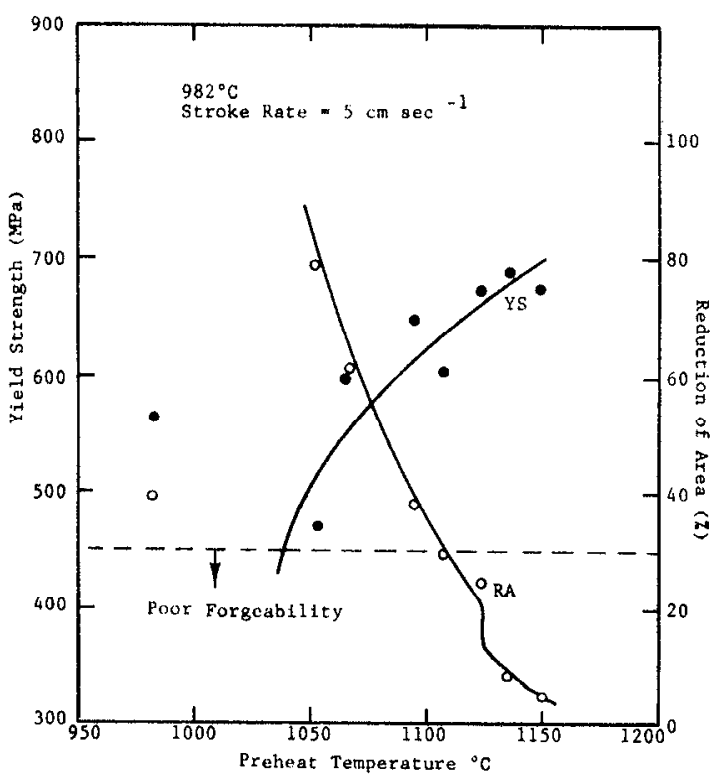

Figure 3. Effect of preheating temperature on the yield strength and ductility of U720. Sample preheated at temperature for 10 minutes, cooled fo $982^{\circ} \mathrm{C}$, then pulled at $5 \mathrm{~cm} \mathrm{sec}$.

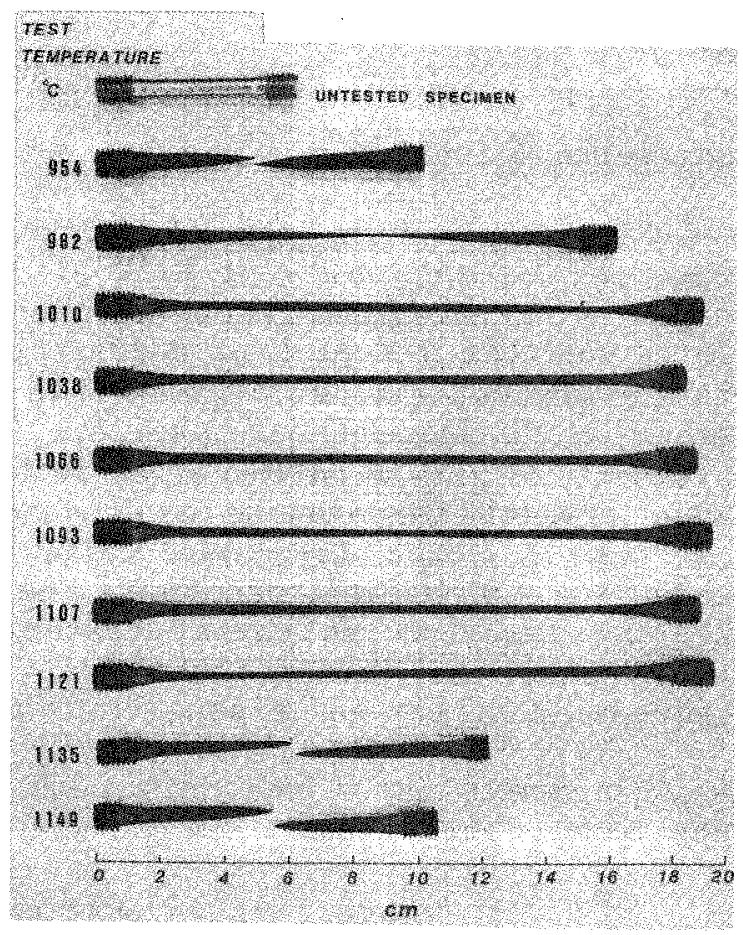

Figure 4. Demonstration of superplasticity in U720. Specimen length was limited by the stroke maximum of test apparatus. 


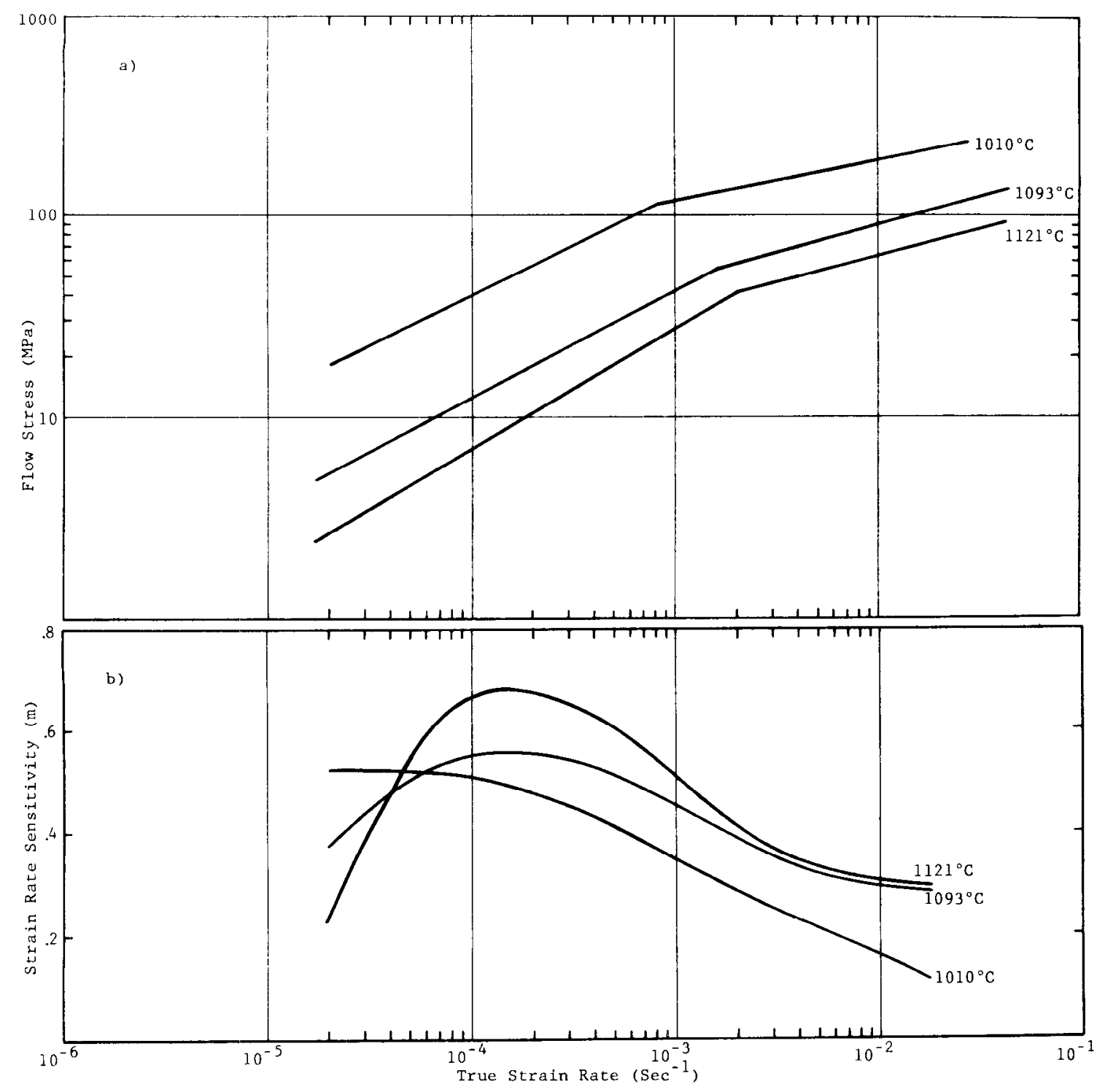

Figure 5. a) Strain rate dependence of flow stress for U720 at different temperatures, b) Strain rate dependence of strain rate sensitivity.

\section{Heat Treatment and Structure}

The development of forging practices for U720 has been paralleled by heat treatment studies to optimize strength and ductility. Figure 7 shows the structures achieved with four different heat treatments. The heat treatment temperatures, times and cooling conditions are listed in Table IV. The best combination of yield strength and ductility at both 650 and $760^{\circ} \mathrm{C}$ was achieved with heat treatment III. A11 of the heat treatments partially solutioned the bimodal $\gamma^{\prime}$ of the as-rolled structure and produced a finer intragranular $\gamma^{\prime}$. Heat treatment I was a high temperature direct age adopted from the blading heat treatment. It left a few areas of fine intragranular $\gamma^{-}$unsolutioned and precipitated a uniform fine intragranular $\gamma^{\prime}$ with very few grain boundary precipitates. Heat treatment II combined a partial solution aimed at retaining a fine grain size with the high temperature aging treatments. The coarse intergranular $\gamma^{\prime}$ 


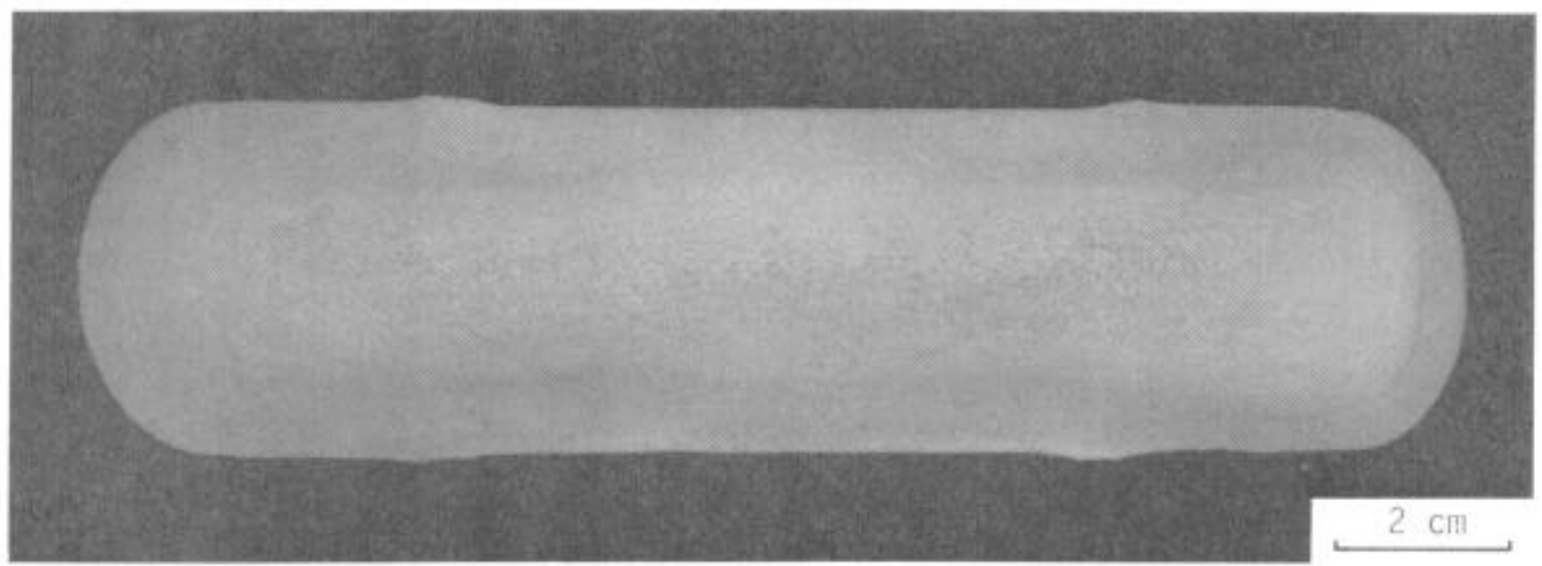

Figure 6. Macroetch section of a hot die forged U720 pancake.

was reduced and the coarser intragranular $\gamma^{\prime}$ was eliminated. An intermediate size $\gamma^{\prime}$ was precipitated intragranularly. Heat treatment III combined a low temperature solution with a lower temperature two step age. It eliminated the coarser intragranular $\gamma^{\prime}$ and formed an intermediate sized intragranular $\gamma^{\prime}$ with some grain boundary precipitation. Heat treatment IV combined the low temperature solution and low temperature aging treatments with the stabilization treatment from the blade heat treatment. The coarse intergranular $\gamma^{\prime}$ was reduced but not as much as in heat treatments I, II or III. A coarse intragranular blocky $\gamma^{\prime}$ was introduced and a hyperfine intragranular $\gamma^{\prime}$ was also formed. This explains the high strength and low ductility obtained with this heat treatment.

Figure 8 shows the effect of solution temperature on room temperature and $704^{\circ} \mathrm{C}$ yield strength and ductility and on grain size of hot die forged material. $1115^{\circ} \mathrm{C}$ was selected as the solution temperature because this temperature gave the best combination of strength and ductility.

Work is continuing to develop information on the effects of forging temperature and heat treat variables such as cooling rate from the solution temperature on structure and mechanical properties of hot die forged U720. Figure 9 shows the effect of quench rate on microstructure of fully heat treated pancakes. Structures varied markedly from a predominantly fine $\gamma^{\prime}$ with very 11 ttle coarse intergranular $\gamma^{\prime}$ and no grain boundary precipitation after a $650^{\circ} \mathrm{C}$ salt quench to a trimodal $\gamma^{\prime}$ with heavy grain boundary precipitation after a $427^{\circ} \mathrm{C}$ salt quench. It is anticipated that these variations in structure will have a significant effect on mechanical properties.

TARLE TV - TENSILE PROPERTIES OE UDIMET 720

\begin{tabular}{|c|c|c|c|c|c|c|c|c|c|c|c|c|}
\hline \multirow{2}{*}{$\frac{\text { Heat }}{\text { Treatment }}$} & \multicolumn{4}{|c|}{ Roca Temperature } & \multicolumn{4}{|c|}{$649^{\circ} \mathrm{C}$} & \multicolumn{4}{|c|}{$760^{\circ} \mathrm{C}$} \\
\hline & $\frac{\text { UTS }}{(\mathrm{MPa})}$ & $\frac{.2 X Y S}{\left(M Y_{B}\right)}$ & $\frac{E 1}{(z)}$ & $\frac{R A}{(z)}$ & $\frac{\text { UTS }}{\left(M P^{\prime}\right)}$ & $\frac{+2 Z Y S}{(M P a)}$ & $\frac{\mathrm{E} 1}{(\bar{z})}$ & $\begin{array}{l}\mathrm{RA} \\
(\mathrm{z})\end{array}$ & $\frac{\text { UTS }}{(\overline{\mathrm{MPa}})}$ & $\frac{.2 X Y S}{(\mathrm{MPa})}$ & $\frac{E 1}{(z)}$ & $\frac{R A}{(X)}$ \\
\hline 1 & 1599 & 1307 & 8.1 & 10.2 & 1363 & 1111 & 25.4 & 26.8 & 942 & 801 & 23.8 & 29.9 \\
\hline II & 1578 & 1187 & 15.3 & 14.1 & 1380 & 1077 & 23.0 & 25.0 & 973 & 859 & 21.2 & 25.0 \\
\hline III & 1575 & 1218 & 11.3 & 12.5 & 1420 & 1107 & 19.7 & 21.3 & 1071 & 996 & 13.4 & 17.4 \\
\hline IV & 1573 & $\begin{array}{l}1191 \\
\mathrm{I}\end{array}$ & 13.4 & 16.0 & $\begin{array}{c}1455 \\
\text { II }\end{array}$ & 1128 & 16.8 & $\begin{array}{l}16.2 \\
\text { III }\end{array}$ & 1154 & 1051 & $\mathrm{IV}^{9.0}$ & 10.4 \\
\hline & $\begin{array}{l}843^{\circ} \mathrm{C} \\
760^{\circ} \mathrm{C}\end{array}$ & $\begin{array}{l}-26 \mathrm{Hr} \\
-16 \mathrm{Hr}\end{array}$ & $\begin{array}{l}-\mathrm{AC} \\
-\mathrm{AC}\end{array}$ & $\begin{array}{r}711 \\
84 \\
766\end{array}$ & $\begin{array}{l}C=2 H \\
C=26 H \\
C-16 H\end{array}$ & $\begin{array}{l}C-A C \\
=A C \\
=A C\end{array}$ & $\begin{array}{r}7113 \\
649 \\
760\end{array}$ & $\begin{array}{l}c=2 \mathrm{Hr} \\
C=24 \mathrm{Hr} \\
\mathrm{C}-8 \mathrm{Hr}\end{array}$ & $\begin{array}{l}-A C \\
-A C \\
=A C\end{array}$ & $\begin{array}{r}1113^{\circ} \\
1079^{\circ} \\
649^{\circ} \\
760^{\circ}\end{array}$ & $\begin{array}{l}=2 \mathrm{Hr} \\
=4 \mathrm{Hr} \\
=24 \mathrm{Hr} \\
=8 \mathrm{Hr}\end{array}$ & $\begin{array}{l}-A C \\
-D Q \\
-A C \\
-A C\end{array}$ \\
\hline
\end{tabular}


Heat

Treatment

I

I.

III

IV
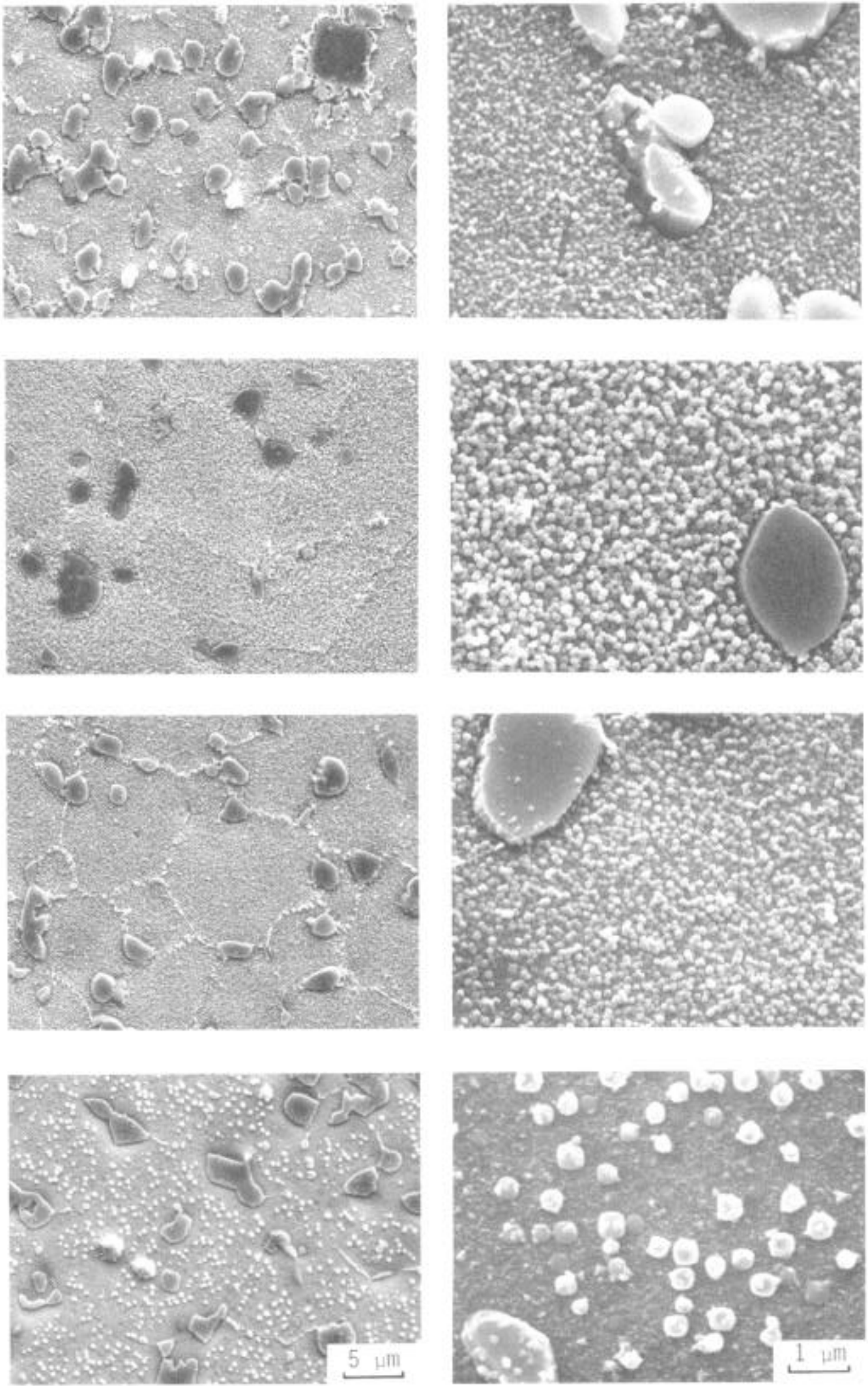

Figure 7. Microstructures achieved using various disk-type heat treatments. Corresponding heat treatment and properties are listed in Table IV 


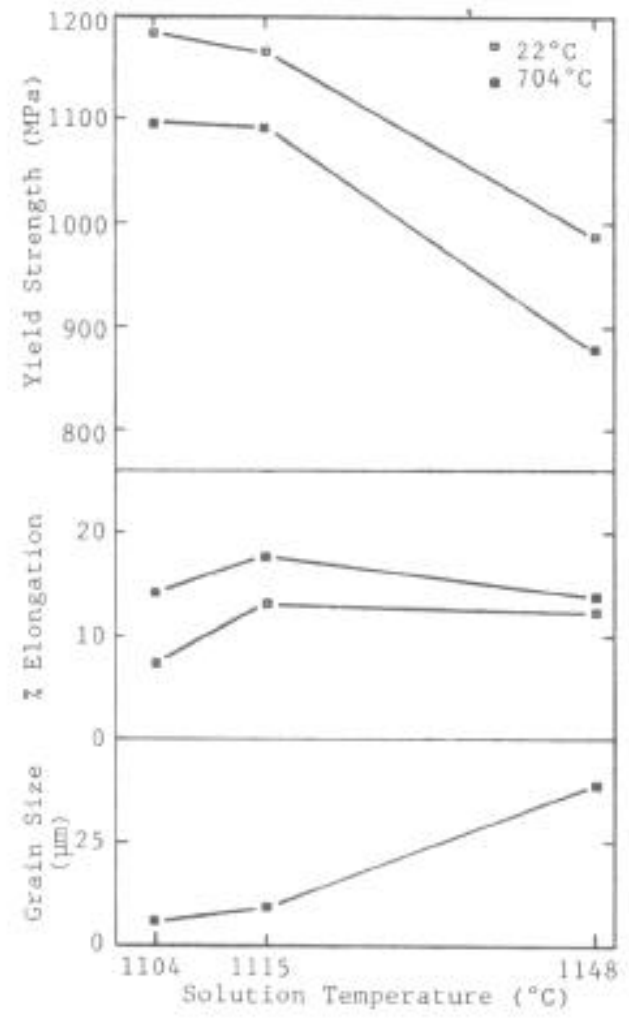

Figure 8. Effect of solution temperature on room temperature and $704^{\circ} \mathrm{C}$ yield strength and ductility and on grain size of hot die forged U720.
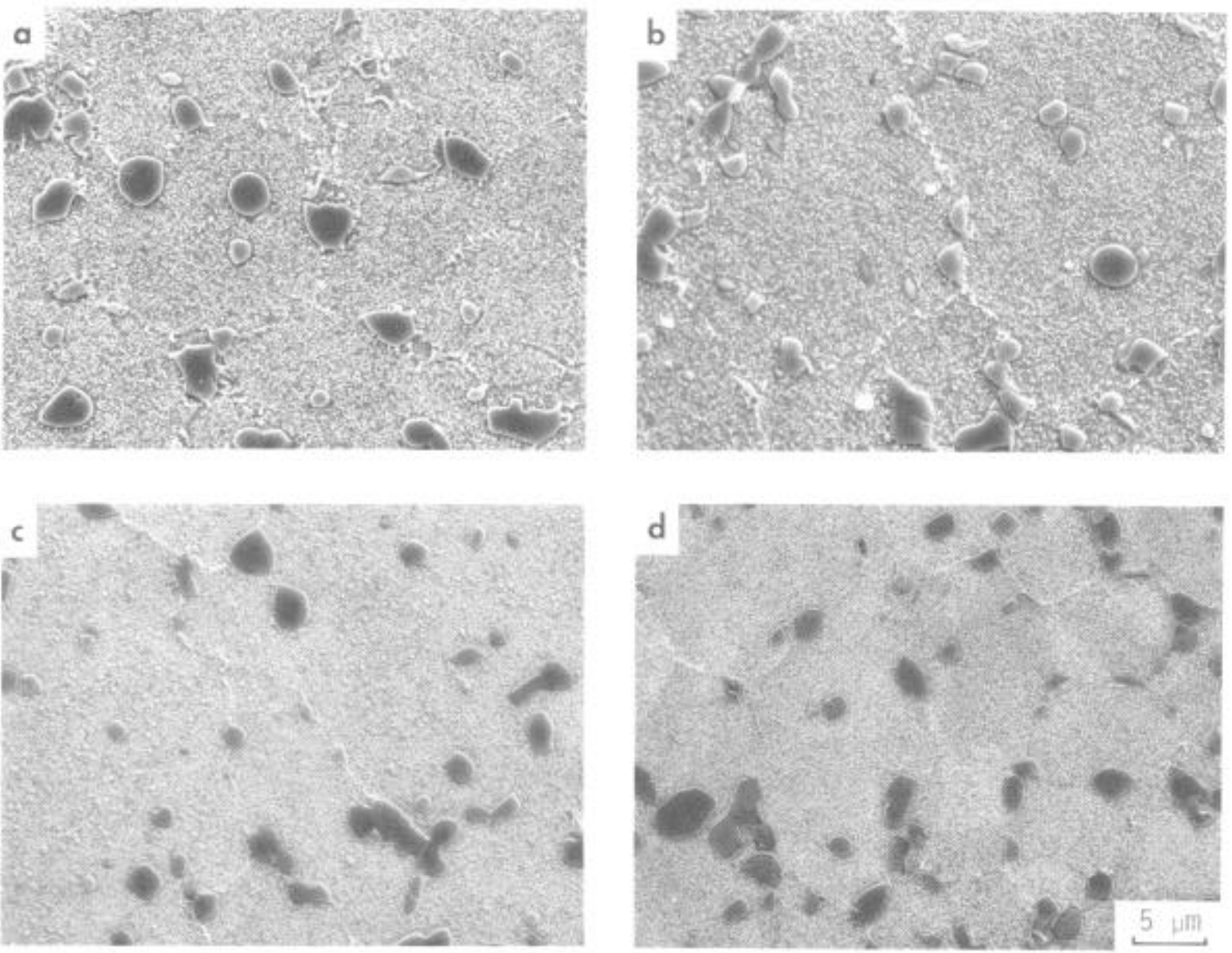

Figure 9. Microstructure of fully aged U720 given different quench rates from solution heat treatment, a. Air Cool, b. $650^{\circ} \mathrm{C}$ Salt, c. $427^{\circ} \mathrm{C}$ Salt, d. Oil Quench. 